\title{
CHOICE OF OSTEOSYNTHESIS IN FRACTURES OF THE PROXIMAL FEMUR IN CHILDREN
}

\section{Nikolay Tarasov, Dmitriy Vybornov, Vladimir Krestyashin, Ilya Petrukhin ${ }^{\bowtie, ~ N a t a l y a ~ T r u s o v a, ~ I v a n ~ I s a e v, ~}$ Vladimir Koroteev, Yuliya Lozovaya, Maksim Golovanev, Ekaterina Kardash, Darya Ti Min Chua, Alexander Grishin}

\section{N.F. Filatov Children's Municipal Clinical Hospital, Moscow \\ N. I. Pirogov Russian national research medical university, Pediatric Surgery Department}

\section{dr.petrukhin@gmail.com}

\section{INTRODUCTION}

Fractures of the femur are some of the serious injuries that occur in childhood. Due to the increasing number of types of extreme sports, the development of infrastructure, an increase in the number of road traffic accidents, these types of fractures are no longer rare and, according to various authors, make up to $16 \%$ of all fractures. Fractures of the proximal femur deserve special attention, which is associated with the peculiarities of the anatomical location. If surgical treatment of such fractures is necessary, the question arises of choosing a method for fixation of fragments. $[2,4,6]$.

\section{MATERIALS AND METHODS}

In the period from 2000 to 2019 in the Unit of Traumatology N.F. Filatov Children's Hospital were treated 725 patients with fractures of the lower extremities. Of them, 332 children - with fractures of the femur, of which 46 children - with fractures of the proximal femur. The largest number were intraarticular fractures (osteoepiphysiolysis of the femoral head) - more than 50\%, femoral neck fractures and intertrochanteric fractures $-12 \%$, fractures of the upper third of the femoral diaphysis - 30\%. The choice of fixators was determined by the anatomical peculiarity of the damaged segment, the plane of the fracture and its proximity to the growth plate, the patient's age and the presence of concomitant pathology. The main criterion for choosing surgical access and implant was bone anatomy and the presence of active growth zones. $[2,4,6]$. It is known that at the age of about 4 to 6 years, ossification of the greater trochanter of the femur occurs, almost complete ossification of the femoral head (except its medial surface) and the ossification of the femoral neck ends. The medial part of the femoral head, the small trochanter, the apex of the greater trochanter, the metaepiphyseal growth plate of the femur in this age interval still have a cartilaginous structure. Starting from 7 years old and pumping in at approximately 10 years of age, the ossification of the femoral head, major and minor trochanters takes place. The proximal metaepiphyseal growth plate, as well as the growth plate of the greater and lesser trochanters, have a cartilaginous structure. At the age of 10 to 14 years, the ossification of the apophyses occurs, and at the age of 15 to 17 years, the final synostosis of the metaepiphyseal sprout of the femur and sprout zones of the greater and lesser trochanters takes place. [5]. Based on the age-related features of bone anatomy, the selection of the fixator was individual and proceeded from the fact that when the implant was placed, the growth plate remained intact. $[4,5]$. The general requirement for choosing the optimal fixation method was minimally invasive and maximum stability with the possibility of early rehabilitation of the patient. According to the AO classification, we dealt mainly with fractures: 31-E / 1.1, 31-M / 2.1, 31-M / 3.1, 31-M / 3.2. [7, 8]. Surgical treatment was carried out during the first 48 hours after admission to the hospital.

Clinical example 1. A 10-year-old child, a boy engaged in the football sports section, fell on his right lower limb during training. A few days after the fall, in connection with severe pain, the parents delivered the child to the clinic. From the moment of injury to the moment of seeking medical help, the child noted an increase in pain in the area of the right hip joint and further impossibility of resting on the right leg. Radiography revealed epiphysiolysis of the head of the right femur with a shift. Minimally invasive osteosynthesis with cannulated screws was performed. The child is upright and discharged from the hospital during the first week. Fixators removed after 15 months (Fig. 1, 2). [3]. Clinical example 2. A boy aged 17 was admitted to the hospital after an injury sustained when falling from a bicycle onto his left lower limb. As a result of the injury, a fracture of the neck of the left femur occurred (Fig. 3). Osteosynthesis was performed by cannulated screws. The result of treatment after 6 months is presented in Fig. 4. [3]. Clinical example 3. A 13-year-old child with a combined injury from a car accident and having a closed overtrochanteric fracture of the right femur with a displacement was selected 


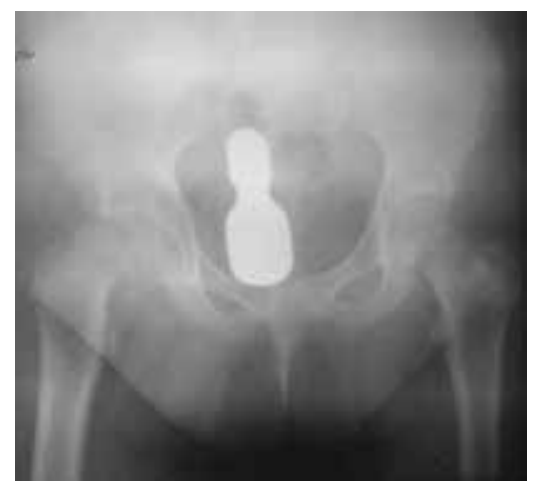

Fig. 1

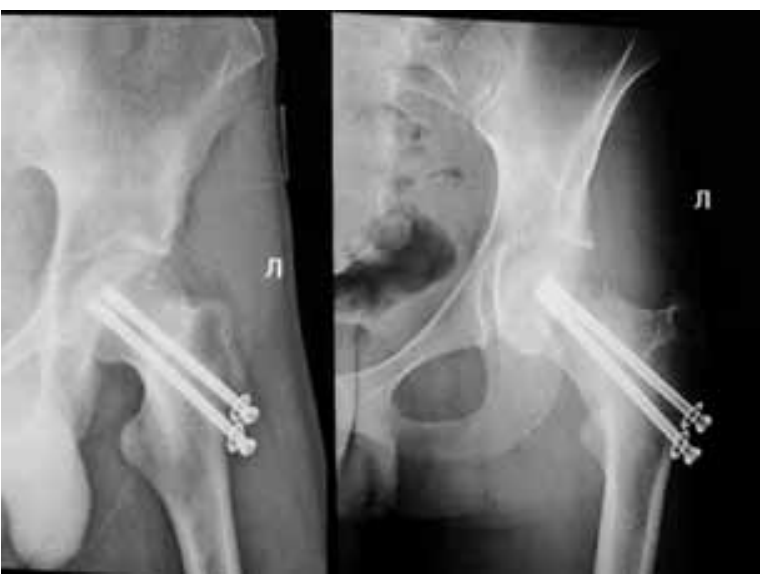

Fig. 4

by the method of osteosynthesis using the Pediatric Hip Plate (PHP) $130^{\circ} 5.0$ (Fig.5, 6 ). To a younger age, with subtrochanteric fractures of the femur located closer to the diaphyseal section of the bone, minimally invasive intramedullary TEN osteosynthesis was performed. Radiographs of a child 5 years old before and 4,5 months after treatment are presented in Fig. 7, 8. [1]. At the oldest ages, children received intramedullary pin fixation. Figure 9, 10 shows the radiographs of one of the clinical cases, a 16-year-old girl who had a pathological fracture of the proximal left femur against a benign aneurysm cyst (the diagnosis was made histologically). Metal osteosynthesis using PFNA and bone grafting supplemented with biocomposite material was performed (Fig. 9, 10).

\section{RESULTS AND DISCUSSION}

Of the variety of fixatives, cannulated screws were used: for osteoepiphysiolysis of the femoral head, lockable plates (PHP) and intramedullary fixators (TEN, PFNA) for intertrochanteric fractures and fractures of the upper third of the femur. Stable-functional os-
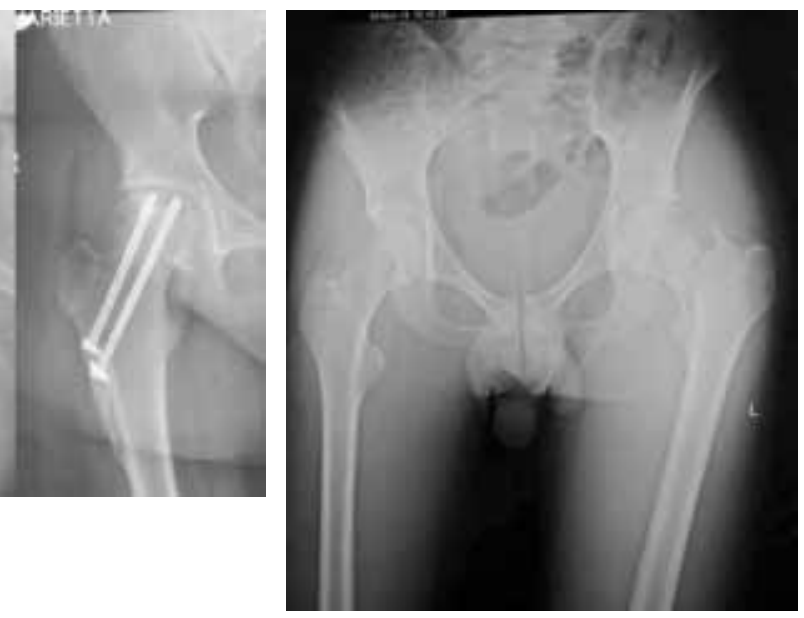

Fig. 3

teosynthesis allowed early start activation of patients. Removal of fixatives was carried out after complete consolidation of the fracture - on average after 6-12 months, depending on age.

\section{CONCLUSIONS}

The use of various types of fixatives for fractures of the proximal femur in children should be strictly individual and create the least trauma to the surrounding anatomical structures when performing osteosynthesis, and subsequent removal of the fixative, without affecting the development and growth of bone. A rational approach when choosing a metal fixator allows for sufficient stability in the fracture area, contributing to the early functional rehabilitation of the injured limb and the prevention of immobilization complications.

\section{REFERENCES}

1. Alberghina F, Andreacchio A, Cravino M, Paonessa M, Canavese F. Extra-articular proximal femur fractures in children and adolescents treated by elastic stable intramedullary nailing. Int Orthop. 2019 Dec;43(12):2849-2856. doi: 10.1007/s00264-01904379-x. Epub 2019 Jul 27.

2. Management of Pediatric Femoral Neck Fracture. Patterson JT, TangtiphaiboonTANA J, PANDYA NK. From the Department of Orthopaedic Surgery, University of California, San Francisco, CA. J Am Acad Orthop Surg. 2018 Jun 15;26(12):411-419. doi: 10.5435/JAAOS-D-16-00362.

3. Palocaren T. Department of Orthopaedics, Christian Medical College, Vellore, Tamil Nadu, India. Femoral Neck Fractures in Children: A Review. Indian J Orthop. 2018 Sep-Oct;52(5):501-506. doi: 10.4103/ ortho.IJOrtho_404_17.

4. Rockwood AND WILkINs Fractures in Children.1252 pages. LWW; Eighth edition (October 


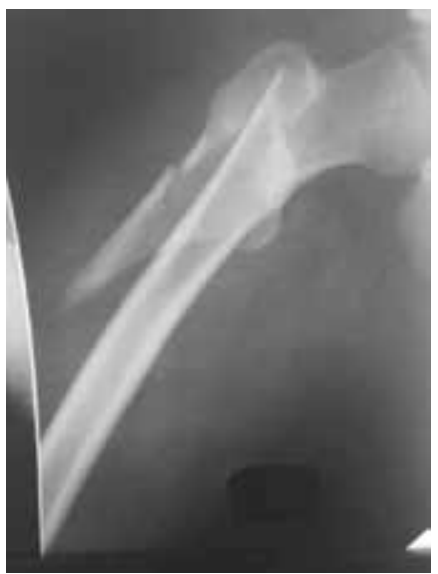

Fig. 5

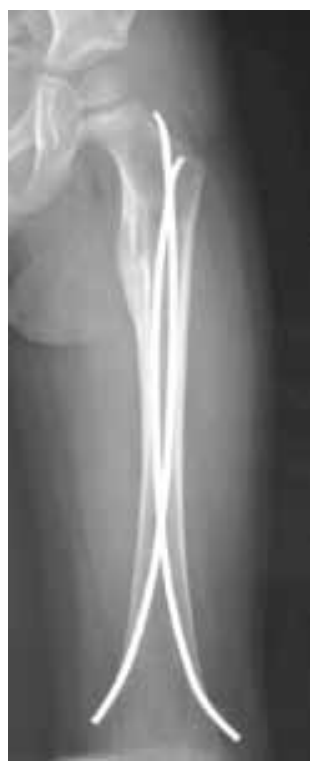

Fig. 8

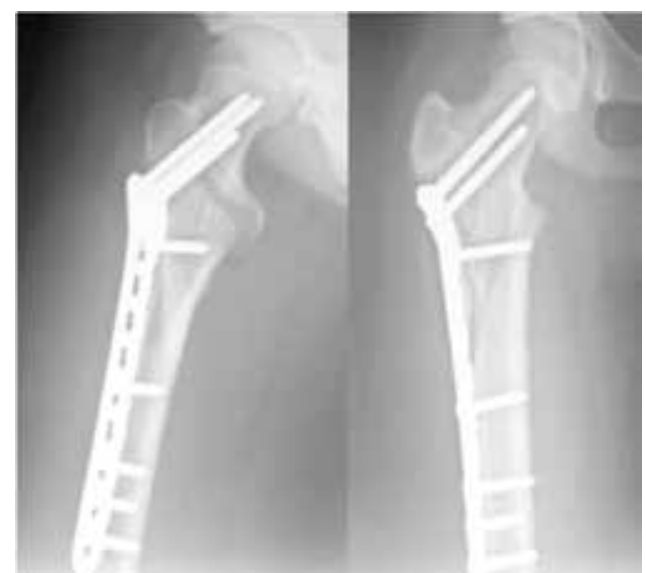

Fig. 6

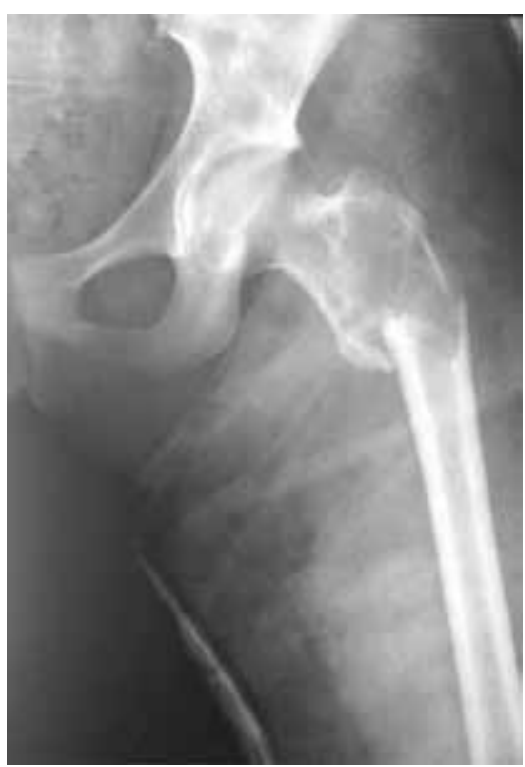

Fig. 9

1, 2014) ISBN-10: 1451143931 ISBN-13: 978 1451143935 .

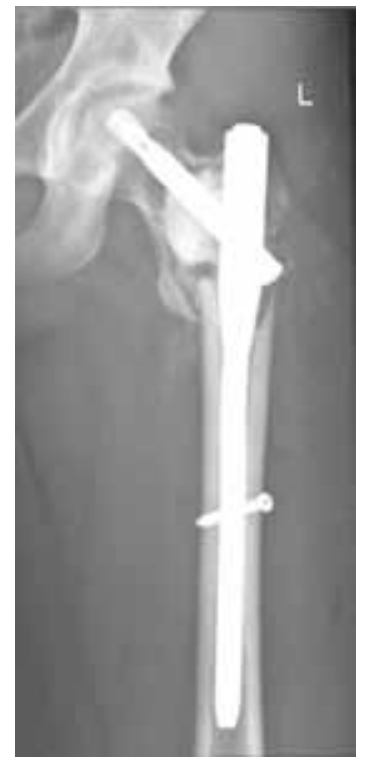

Fig. 10

5. SAdOFIEva VI. Normal X-ray anatomy of the osteoarticular system of children. LENINGRAD "MEDICINE" Leningrad branch 1990.

6. Sankar WN, Mehlman CT. The Community Orthopaedic Surgeon Taking Trauma Call: Pediatric Femoral Neck Fracture Pearls and Pitfalls. J Orthop Trauma. 2019 Aug;33 Suppl 8:S22-S26. doi: 10.1097/ BOT.0000000000001541.

7. https://www2.aofoundation.org/wps/portal/surgery.

8. https://radiopaedia.org/articles/proximal-femoralfractures. 